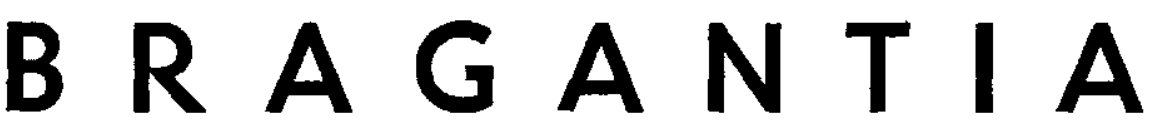

Revista Cientifica do Instituto Agronómico do Estado de São Paulo

Vol. 34

Campinas, outubro de 1975

N. ${ }^{\circ} 19$

\title{
ESTUDO COMPARATIVO PRELIMINAR ENTRE CULTIVARES DE TRITICALE E UM CULTIVAR DE TRIGO NO ESTADO DE SÃO PAULO $\left({ }^{1,2}\right)$
}

Carlos Eduardo de Oliveira Camargo $\left({ }^{3}\right)$ e João Carlos Felfcio, Segão de Arroz e Cereais de Inverno, Instituto Agronômico

\section{SINOPSE}

Foram instalados no ano de 1973, dols ensaios comparativos entre quinze cultivares de triticale (híbrido de trigo com centeio) e o cultivar de trigo IAC-5, cultivado no Estado de Săo Paulo, sendo um deles localizado no Centro Experimental de Campinas e o outro na Fazenda São Giórgio I, município de Cruzália, São Paulo.

O cultivar de trigo IAC-5 e o cultivar de triticale I-44424 foram os que apresentaram maiores produçōes de gráos por hectare, na média dos dois experimentos.

Não houve diferença estatistica entre os cultivares de triticale e o cultivar de trigo estudado, quanto à produçâo de palha seca por área, considerando em conjunto o ensalo de Campinas e Cruzália.

Os triticales foram resistentes as ferrugens do colmo e da folha, mas os seus grāos mostraram-se com o aspecto não desejado de enrugamentos na superfície.

\section{1 - INTRODUÇÃO}

O cereal triticale foi inicialmente uma curiosidade biológica, porém, atualmente, tem possibilidades de chegar a ser cultivado com igual importância às das espécies progenitoras (1). $O$ triticale se originou por hibridação de duas espécies distintas: trigo (Triticum spp) e centeio (Secale cereale L.).

(1) Recebido para publicação em 21 de julho de 1975.

(2) Os autores agradecem ao Engenheiro Agrônomo Derly Machado de Souza a colaboraç̄o na realização deste trabalho.

(3) Com bolsa de suplementação do C.N.Pq. 
Foi estimado (1) que o primeiro uso comercial desta cultura seria para a alimentaçăo do gado, pois suas plantas vigorosas produzem excelente forragem. Como grão para alimentação animal, as provas preliminares feitas em Manitoba, Canadá e em alguns locais dos Estados Unidos, indicaram que os triticales são bastante semelhantes ao trigo e à cevada quanto ao nível de proteínas.

Os trabalhos realizados no Centro Internacional de Melhoramento de Milho e Trigo, México, mostraram que, em ensaios comparativos de rendimento, plantados nos anos de 1968 a 1970 , os triticales não produziram mais do que os cultivares de trigo empregados como testemunhas (3). A maior produçáo de grāos dos triticales verificou-se no ensaio de Navojoa (México) em $1969 / 70$, com $5066 \mathrm{~kg} / \mathrm{ha}$, enquanto os trigos produziram $5321 \mathrm{~kg} / \mathrm{ha}$.

O enrugamento das sementes é um dos principais problemas encontrados em todos os triticales devido ao desenvolvimento anormal do endosperma após a fertilização (4).

Com o objetivo de estudar o comportamento dos diferentes cultivares de triticale, introduzidos do México pelo Instituto Agronômico, foram conduzidos dois experimentos aqui relatados, instalados em duas diferentes regiôes do Estado de São Paulo: Centro Experimental de Campinas, do Instituto Agronômico, e Fazenda São Giórgio I, município de Cruzália SP, de propriedade do Sr. Michele Di Raimo.

\section{2 - MATERIAL E METODOS}

O delineamento estatístico empregado foi o de blocos ao acaso, com quatro repetiçōes por local.

Foram utilizados dezesseis tratamentos: quinze compostos de diferentes cultivares de triticale e um pelo cultivar de trigo IAC-5, como controle.

Entre os cultivares de triticale dez procederam do Centro Internacional de Melhoramento de Milho e Trigo, México, tendo sido trazidos pelo Engenheiro Agrônomo Dr. Carlos Arnaldo Krug. Foram encaminhados à Seção de Botânica Econômica do Instituto Agronômico no dia 22 de outubro de 1969, recebendo os seguintes números de registro:

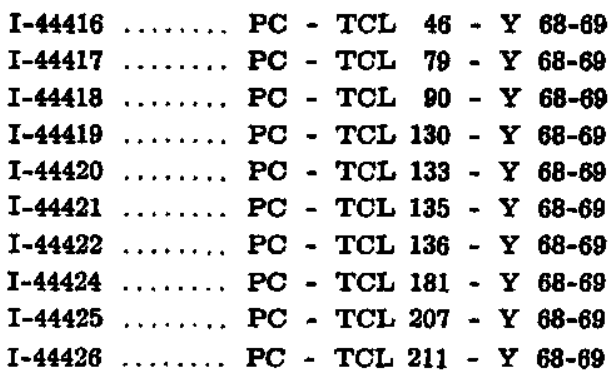


Os demais cultivares de triticale experimentados foram introduzidos de Salinas, Califórnia, Estados Unidos, recebendo os seguintes números de registro:

\begin{tabular}{|c|c|c|}
\hline I- 43975 & & 6 TA 202 \\
\hline$I-43976$ & & 6 TA 204 \\
\hline$I-43977$ & $\ldots$ & 6 TA 206 \\
\hline I-43978 & . & 208 \\
\hline$I-43979$ & $\ldots \ldots$ & 6 TA 209 \\
\hline
\end{tabular}

Anteriormente ao plantio, foram retiradas amostras compostas dos solos dos locais estudados, cujos resultados analíticos ( $\left.{ }^{4}\right)$ foram os seguintes:

Determinagóes

pH int $\ldots \ldots \ldots \ldots \ldots \ldots \ldots \ldots \ldots$

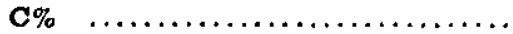

$\left.\mathbf{K}^{+}{ }^{5}\right) \ldots \ldots \ldots \ldots \ldots \ldots \ldots \ldots \ldots$

$\mathrm{Ca}^{2+}+\mathrm{Mg}^{2+}\left({ }^{5}\right) \ldots \ldots \ldots \ldots \ldots \ldots$

$\left.\mathbf{P O}_{4}^{-3} \quad{ }^{\left({ }^{3}\right.}\right) \ldots \ldots \ldots \ldots \ldots \ldots \ldots \ldots$

$\mathbf{A l}^{3+}$

\section{Campinas}

5,11

2,60

0,26

2,32

0,09

0,60
Cruzalia

6,18

2,30

0,42

5,79

0,05

No ano de 1973, o ensaio foi semeado no dia 15 de março no Centro Experimental de Campinas e no dia 25 de abril, na Fazenda São Giórgio I, município de Cruzália.

Cada ensaio foi formado de 64 parcelas, sendo que cada parcela foi constituída de sete linhas de 5 metros de comprimento, espaçadas de 0,20 metro.

A semeadura foi feita na base de 40 sementes viáveis por metro de sulco, equivalendo a 1400 plantas por parcela, e por ocasião da colheita foram colhidas as cinco linhas centrais de cada parcela, deixando as demais como bordaduras, portanto com uma área útil de $5 \mathrm{~m}^{2}$.

A adubação utilizada, aplicada totalmente no sulco de plantio, compunha-se de $30 \mathrm{~kg}$ de N, $90 \mathrm{~kg}$ de $\mathrm{P}_{2} \mathrm{O}_{5}$ e $20 \mathrm{~kg}$ de $\mathrm{K}_{2} \mathrm{O}$, por hectare, nas formas respectivamente de sulfato de amônio com $20 \%$ de $\mathrm{N}$, superfosfato simples com $20 \%$ de $\mathrm{P}_{2} \mathrm{O}_{5}$, e cloreto de potássio com $60 \%$ de $\mathrm{K}_{2} \mathrm{O}$.

A descrição detalhada dos caracteres estudados e os métodos de determinação são apresentados a seguir:

A altura das plantas de cada cultivar fol medida no campo, levando-se em conslderaçáo a distancia do nivel do solo ao ápice da espiga, mantendo-se as plantas esticadas.

O periodo em dias, da germinaçăo a maturaçăo completa de cada cultivar, fol caracterizado como ciclo.

(4) Análise efetuada pela Seção de Fertilidade do Solo, Instituto Agronómico.

(s) e. $\mathrm{ma} / 100 \mathrm{ml}$ de solo. Teores trocáveis.

(6) e. $\mathrm{mg} / 100 \mathrm{ml}$ de solo. Teor solúvel em H $\$$ 
A ocorrência de ferrugem do colmo (Pucelnia graminis Pers. forma sp. triticl Eriks. et E. Henn.) e de ferrugem da folha (Puccinia recondita Rob. ex Desm.) fol avaliada levando-se em conta a área da planta atacada expressa em porcentagem e os tipos de reação ou de infecção (5).

Dos ensalos de Campinas e Cruzália foram classificados os grãos dos diferentes cultivares quanto ao aspecto, obedecendo ao seguinte critério: muito bom, quando o grão apresentava aspecto normal, isto é, sem enrugamento; bom, quando mostrava pouco enrugamento; regular, quando o grão se apresentava medianamente enrugado; e ruim, quando o gräo estava bastante enrugado (desenvolvimento anormal do endosperma).

\section{3 - RESULTADOS E DISCUSSÃO}

As produções médias de grãos e palha seca de cada experimento encontram-se no quadro 1.

$\mathrm{Na}$ análise dos dois experimentos em relação à produção de grãos, verificaram-se efeitos altamente significativos para cultivares, e efeito significativo para a produção de palha seca nos diferentes locais.

QUADRO 1. - Produçóes médias dos cultivares de triticale e do cultivar de trigo IAC-5 estudados em ensaios comparativos, no ano de 1973, no Centro Experimental de Campinas e na Fazenda Săo Giórgio I, municipio de Cruzália, SP

\begin{tabular}{|c|c|c|c|c|c|c|}
\hline \multirow{3}{*}{ CULTIVAR } & \multirow{2}{*}{\multicolumn{2}{|c|}{ Campinas }} & \multirow{2}{*}{\multicolumn{2}{|c|}{ Cruzália }} & \multirow{2}{*}{\multicolumn{2}{|c|}{$\frac{\text { Média geral }}{\text { Campinas/Cruzália }}$}} \\
\hline & & & & & & \\
\hline & Grāos & Palha & Grãos & Palha & Grãos & Palha \\
\hline & $\mathrm{kg} / \mathrm{ha}$ & $\tan / \mathrm{ha}$ & $\mathbf{k g} / \mathbf{h a}$ & ton/ha & $\mathbf{k g} / \mathbf{h a}$ & tor:ha \\
\hline 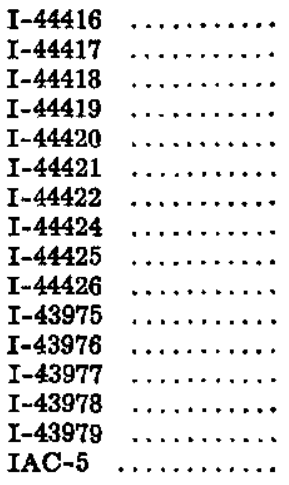 & $\begin{array}{r}887 \\
1317 \\
1177 \\
958 \\
1123 \\
1087 \\
1036 \\
1867 \\
1764 \\
1716 \\
795 \\
1939 \\
913 \\
1046 \\
988 \\
1911\end{array}$ & $\begin{array}{r}7,04 \\
10,39 \\
6,03 \\
9,18 \\
8,59 \\
7,34 \\
8,18 \\
8,92 \\
6,23 \\
10,57 \\
12,70 \\
10,49 \\
11,30 \\
11,52 \\
9,30 \\
11,56\end{array}$ & $\begin{array}{r}1817 \\
2357 \\
1855 \\
1924 \\
2208 \\
1899 \\
2141 \\
2978 \\
2451 \\
2542 \\
916 \\
2324 \\
737 \\
759 \\
736 \\
3311\end{array}$ & $\begin{array}{r}9,82 \\
11,71 \\
10,57 \\
8,90 \\
9,57 \\
9,31 \\
10,21 \\
12,16 \\
10,12 \\
11,81 \\
10,12 \\
11,89 \\
11,58 \\
10,31 \\
9,12 \\
8,51\end{array}$ & $\begin{array}{r}1352 \\
1837 \\
1516 \\
1441 \\
1666 \\
1493 \\
1588 \\
2423 \\
2107 \\
2129 \\
855 \\
2131 \\
825 \\
902 \\
862 \\
2611\end{array}$ & $\begin{array}{r}8,43 \\
11,05 \\
8,30 \\
9,04 \\
9,08 \\
8,33 \\
9,19 \\
10,54 \\
8,18 \\
11,19 \\
11,41 \\
11,19 \\
11,44 \\
10,92 \\
9,21 \\
10,03\end{array}$ \\
\hline 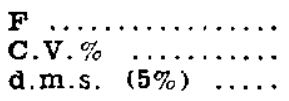 & $\begin{array}{c}23,74^{* *} \\
13,07 \\
431\end{array}$ & $\begin{array}{c}9,82^{* *} \\
13,77 \\
3,30\end{array}$ & $\begin{array}{c}37,68^{* *} \\
13,31 \\
662\end{array}$ & $\begin{array}{c}2,92 * * \\
13,13 \\
3,50\end{array}$ & $\begin{array}{c}4,55^{* *} \\
13,19 \\
1528\end{array}$ & $\begin{array}{c}3,64 \text { n.s. } \\
13,45 \\
6,12\end{array}$ \\
\hline
\end{tabular}

(*) significativo ao nivel de $1 \%$.

(n.s.) nāo significativo estatisticamente. 
A análise conjunta dos ensaios de Campinas e Cruzália quanto à produção de palha seca mostrou efeito não significativo para cultivares, efeito altamente significativo para locais e interação cultivares $\mathrm{x}$ locais.

Os resultados alcançados em Campinas mostram que o triticale I-43976 foi superior quanto à produção de grãos, porém não diferiu estatisticamente pelo teste do Tukey a $5 \%$ dos triticales I-44424, I-44425, I-44426 e do cultivar de trigo IAC-5.

O cultivar IAC-5 produziu maior quantidade de grãos por área em Cruzália, diferindo pelo teste de Tukey a $5 \%$ de todos os triticales estudados, com exceção do I-44424.

Considerando as produções médias de grãos em $\mathrm{kg} / \mathrm{ha}$ dos dois ensaios, verificou-se que o cultivar de trigo IAC-5 foi o mais produtivo, porém diferindo estatisticamente somente dos triticales I-43979, I-43978, I-43977 e I-43975.

Quanto à produção de palha seca destacou-se, em Campinas, o triticale I-43975, não diferindo, porém, pelo teste de Tukey a 5\%, dos triticales I-44417, I-44426, I-43976, I-43977, I-43978 e do trigo IAC-5. Em Cruzália o triticale I-44424 foi superior estatisticamente ao cultivar IAC-5, em relação à produção de palha.

Observando o quadro 2, verifica-se que todos os cultivares de triticale mostraram-se resistentes às ferrugens do colmo e da folha, enquanto o cultivar IAC-5 de trigo mostrou suscetibilidade a ambas as doenças.

QUADRO 2. - Caracteristicas dos cultivares de triticale e do cultivar IAC-5 de trigo, estudados em ensajos comparativos no ano de 1973

\begin{tabular}{|c|c|c|c|c|c|}
\hline CULTIVAR & $\begin{array}{c}\text { Altura } \\
\text { da planta }\end{array}$ & Ciclo & $\begin{array}{l}\text { Ferrugem } \\
\text { do colmo }\end{array}$ & $\begin{array}{l}\text { Ferrugem } \\
\text { da folha }\end{array}$ & $\begin{array}{l}\text { Aspecto } \\
\text { do grão }\end{array}$ \\
\hline & $\mathrm{cm}$ & dias & & & \\
\hline$I-44416 \ldots \ldots$ & 108 & 118 & 0 & 0 & bom \\
\hline I-44417 & 122 & 120 & $\mathbf{0}$ & 0 & regular \\
\hline$I-44418 \ldots \ldots \ldots \ldots$ & 115 & 120 & 0 & 0 & regular \\
\hline I-44419 $\ldots \ldots$ & 115 & 118 & 0 & $\mathbf{0}$ & bom \\
\hline $\bar{I}-44420 \ldots \ldots \ldots \ldots$ & 118 & 120 & $\mathbf{0}$ & 0 & ruim \\
\hline I-44421 $\ldots$ & 113 & 120 & $\mathbf{0}$ & 0 & bom \\
\hline I-44422 $\ldots$ & 112 & 118 & $\mathbf{0}$ & 0 & bom \\
\hline$I-44424 \ldots \ldots$ & 105 & 120 & $\mathbf{0}$ & 0 & bom \\
\hline$I-44425 \ldots \ldots \ldots$ & 105 & 120 & 0 & o & regular \\
\hline$I-44426 \ldots \ldots \ldots \ldots$ & 105 & 120 & 0 & 0 & bom \\
\hline$I-43975 \ldots \ldots \ldots$ & 120 & 150 & 0 & $\mathbf{0}$ & ruim \\
\hline I-43976 .. & 125 & 120 & 0 & $\mathbf{0}$ & bom \\
\hline$I-43977 \ldots \ldots$ & 130 & 150 & 0 & $\mathbf{0}$ & ruím \\
\hline I-43978 & 125 & 150 & 0 & $\mathbf{0}$ & ruim \\
\hline I-43979 $\ldots$ & 130 & 150 & 0 & $\mathbf{0}$ & ruim \\
\hline IAC-5 $\ldots \ldots$ & 115 & 118 & $5 \mathrm{~S}$ & $30 \mathrm{~S}$ & muito bom \\
\hline
\end{tabular}


Todos os triticales apresentaram seus grãos com enrugamento. Os que mostraram melhor aspecto foram I-44416, I-44419, I-44421, I-44424, I-44426 e I-43976.

Os grãos do cultivar de trigo IAC-5 tiveram desenvolvimento normal do endosperma e muito bom aspecto.

Em razão do bom comportamento dos triticales quanto à produção de grãos e à fitossanidade, estes ensaios serão repetidos nos próximos anos, para a obtenção de informações mais precisas sobre a cultura.

\section{4 - CONCLUSÓES}

a) O cultivar de trigo IAC-5 e o cultivar de triticale I-44424 foram os que apresentaram maiores produções de grãos por hectare, porém só diferindo estatisticamente dos triticales I-43979, I-43977 e I-43975.

b) Não houve diferença estatística entre os, cultivares estudados quanto à produção de palha seca em ton/ha, na média dos dois experimentos, porém em Campinas destacou-se o triticale I-43975, e em Cruzália o I-44424.

c) Os diferentes cultivares de triticale foram resistentes às ferrugens do colmo e da folha, mas apresentaram enrugamento nos grãos.

d) O cultivar de trigo IAC-5 produziu grãos com muito bom aspecto.

e) Entre os cultivares de triticale estudados destacaram-se I-44416, I-44419, I-44421, I-44422, I-44424, I-44426 e I-44976.

\section{A COMPARATIVE STUDY OF TRITICALE CULTIVARS AND WHEAT CULTIVAR IAC-5 IN THE STATE OF SAO PAULO}

\section{SUMMARY}

Competition trials of fifteen cultivars of triticale and one cultivar of wheat (Triticum aestivum L.) were carrled out without irrigation in two different areas of the State of Săo Paulo, in 1973.

The wheat cultivar IAC-5 and the triticale cultivar I-44424 showed good grain production per hectare.

There were no significant differences among the treatments in relation to straw production per area.

The cultivars of triticale presented good resistance to stem and leat rusts but their grains showed a wrinkled surface. The degree of wrinkledness varled prom cultivar to cultivar. 


\section{LITERATURA CITADA}

1. CENTRO INTERNACIONAL DE MEJORAMUENTO DE MAIZ $Y$ TRIGO. Informe anual. México, 1969-70. 138p.

2. GOMES, F. P. Curso de estatística experimental. Piracicaba, Escola Superior de Agricultura "Luiz de Queiroz", 1963. 384p.

3. NOTICIGRO DEL CIMMYT. México, v. 4, n. 3/4, 1969.

4. —. 5, n. 5/8, 1870.

5. STAKMAN, E. C.; LEVINE, M. N. \& LOEGERING, N. Q. Identification of physiologic races of Puecinia graminis triticl. Washington, USDA Agricultural Research Administration, 1944. 72p. 